\title{
Final deliveries for online shopping: The deployment of pickup point networks in urban and suburban areas
}

\author{
Eleonora Morganti * ${ }^{*}$ Laetitia Dablanc ${ }^{1}$, François Fortin ${ }^{2}$ \\ French Institute of Sciences and Technology for Transport, Development and Networks IFSTTAR-SPLOTT, Cité Descartes, 14-20 Boulevard Newton, 77447 Marne-la-Vallée cedex 02, France
}

\section{A R T I C L E I N F O}

\section{Article history:}

Received 30 September 2013

Received in revised form 11 March 2014

Accepted 11 March 2014

Available online 2 April 2014

\section{Keywords:}

E-commerce

Final delivery

Urban freight

Pickup point

\begin{abstract}
A B S T R A C T
In France, e-commerce has experienced steady growth over the past decade. A striking aspect is that it is now widespread among different segments of the population, including suburban and rural households. This growth has generated significant demand for dedicated delivery services to end consumers. Pickup points (PP) represent a fast-growing alternative to home delivery, accounting for about $20 \%$ of parcel deliveries to households. The article focuses on the strategy of PP network operators. Our results are threefold. We have documented the recent development of alternative parcel delivery services to e-shoppers in Europe, and especially in France. We have described how the operators have decided to organize their PP network, identifying main variables and constraints. We have provided an analysis of the spatial distribution of PPs in France. The paper shows that at the French national level, PPs are now a well established alternative to home deliveries and their presence covers urban, suburban and rural areas. While PP density in remote areas decreases faster than population density, rural e-consumers' accessibility to PP sites has reached a viable level. Furthermore, PP delivery services generate new types of B2B freight trips that are not yet included in current urban freight models.
\end{abstract}

(c) 2014 Elsevier Ltd. All rights reserved.

\section{Introduction}

As in many European countries, shopping habits in France are changing fast. E-commerce is becoming increasingly common due to the spread of IT systems such as laptops, tablets and smartphones. In 2012 e-commerce accounted for 7\% of the French retail market (excluding food), i.e. $€ 45$ billion, with revenue up by $19 \%$ compared with 2011 (FEVAD, 2012). Interestingly, a few authors (Moati, 2009) have reported that online shopping has become widespread among the different segments of the population whether they live in central, suburban or even rural areas, although this change has not been documented in a comprehensive manner. Over the past 10 years, the spread of online shopping has generated significant demand for dedicated delivery services to the end consumer. This has resulted in the increasing fragmentation of shipments in the "last mile" as the final segment of the supply chain is known (Esser, 2006; Schewel \& Schipper, 2012). Currently, in France, the vast majority of the 300 million parcels generated annually by distance selling result from online shopping (ARCEP, 2013).

\footnotetext{
* Corresponding author. Tel.: +331816687 97; fax: + 33181668001.

E-mail addresses: eleonora.morganti@ifsttar.fr (E. Morganti), laetitia.dablanc@ifsttar.fr (L. Dablanc), francois.fortin@ifsttar.fr (F. Fortin).

1 Tel.: + 331816687 78; fax: +33181668001.

2 Tel.: + 33181668931 ; fax: + 33181668001 .
}

Consequently, e-commerce increases the challenges facing product distribution, with direct effects on logistics systems in urban and suburban areas where traffic congestion and accessibility are crucial factors. In the case of the business to consumer market (B2C), home deliveries constitute the most problematic solution in terms of service costs and organization (Song, Cherrett, McLeod, \& Wei, 2009). Although home deliveries are usually preferred by online shoppers (CREDOC, 2010), we are seeing the development of alternatives which satisfy both consumer demand for flexibility and firms' need to optimize parcel distribution through consolidated shipments. In Europe, automated parcel stations (APS) equipped with lockers, and pick-up points (PP), which are stores providing parcel drop-off and pick up services, are fast-growing solutions. These two end-delivery options are playing a decisive role in the reorganization of commercial and logistics activities (Augereau \& Dablanc, 2008) and are becoming key features of the strategy of ecommerce and transport players. In the US, the online giants Amazon and Google (Google has opened an internet sales platform based on Amazon's market place) recently decided to invest in their own branded locker box solutions and are in the process of deploying pilot pickup/ drop off sites. Similarly, in France new players are constantly emerging and new partnerships being set up, such as the takeover of the Kiala PP network by UPS in February 2012, and the takeover of the Pickup Services PP network by the French company La Poste, via its subsidiary GeoPost in 2009.

Currently, in Europe, the largest APS network is the Packstation network operated by DHL/Deutsche Post in Germany (2500 locations 
around the country). Locker box networks have a limited presence in France, as witnessed by the very small network of 33 kiosks run by La Poste under the name of Cityssimo. New operators such as ByBox (originally from the UK) are likely to extend these services in Europe in the coming years. The second alternative, which forms the focus of this paper, is PP networks. In France, four competing providers are growing rapidly and managing increasingly large volumes of parcels. These operators - Mondial Relay, Relais Colis, Kiala and Pickup Services - have developed standardized delivery solutions for the whole country and in 2013 each of the networks provides access to a pickup point in under 10 min by car or on foot (depending on the area) to $90 \%$ of the French population. Today in France, more than $20 \%$ of online shopping shipments are delivered through a PP instead of to home.

According to the European Commission Green Paper on the parcel delivery market for e-commerce (2012), the growth potential of reception point delivery systems in the European Union is strong. It is probable that in the near future, drop-off and collection schemes will account for a significant share of parcel volume and will evolve into a more structured distribution channel, affecting urban logistics practices and enhancing competitiveness. The rapid development of alternative solutions for parcel distribution is confirmed by reports and studies dealing with trends affecting the internet economy and consumer shopping behaviors (Bourdin, 2012; Nemoto, Visser, \& Yoshimoto, 2001; Rallet \& Perrin Boulonne, 2010).

Previous research on end-delivery movements for e-commerce has mostly focused on describing and modeling household shopping trips (Gonzalez-Feliu, Ambrosini, \& Routhier, 2012). In particular home delivery, the core business for shippers and couriers, has been thoroughly investigated during the last decade (Browne, 2001; Punakivi \& Saranen, 2001; Taniguchi and Kakimoto, 2003; Visser, Nemoto, \& Browne, 2013), as has grocery shopping (Cairns, 1996; Wygonik \& Goodchild, 2012). However, with regard to e-commerce delivery schemes, little is known about proximity reception points and site location criteria, trip chain patterns, and tracking and tracing ICT tools. Song et al. (2009) investigated the effect of failed deliveries, estimating customer traveling costs and the environmental costs of home delivery against potential PP networks based on post offices, supermarkets and railway stations across West Sussex in the United Kingdom. In France, the topic has barely been studied.

The aim of this paper is to provide a better understanding of recent developments in urban freight logistics for alternative parcel delivery services to e-shoppers. Our work is part of a broader research program (2012-2015) that looks at disparities in access to e-commerce and home deliveries among urban, suburban and rural residents in France (Motte-Baumvol \& Belton-Chevallier, 2012). We focused our research on PP service providers. It depicts the structure of French PP networks and the strategy of operators when designing PP networks. It provides an analysis of the locational patterns of PP networks and assesses disparities of access to PPs in urban, suburban and rural areas. We have conducted a case study on the Seine-et-Marne Department, a large area to the East of the city of Paris. Seine-et-Marne is partially integrated within the Paris metropolitan area, with urban and suburban settings, but it also has some rural areas, providing an interesting example of diverse residential environments and enabling comparisons. A final objective of this work is to provide directions for future research looking at the impacts of e-commerce on mobility and city logistics. Identifying some of the variables related to parcel flows within PP networks can help us better understand and plan for the traffic generated by city logistics.

Section two of the article describes recent changes and the main PP networks in the current European and French contexts. Section three presents the conceptual framework and methodology applied to the research. Section four describes the strategy of PP network operators. Section five provides a spatial analysis of PP deployment in Seineet-Marne. Section six draws conclusions and opens up discussion for further research.

\section{The development of PP networks in the end-delivery sector}

\subsection{Alternatives to home delivery services}

Our analysis is structured on the basis of the two categories identified by Augereau and Dablanc (2008): (i) pickup points (PP) and (ii) automated lockers. PP networks operate through local shops where packages generatedby the distance selling market are dropped off for collection by their individual recipients. In general, PPs are attended 6 days a week, during the opening hours of their host business (dry cleaners, florists, etc.). The second category refers to networks of APS, where people can withdraw packages $24 \mathrm{~h}$ a day from locker boxes usually located in shopping centers, gas stations, train stations or on the street. The strength of both systems is the flexibility of opening times compared with post offices, giving consumers the option to withdraw their packages at the time that suits them, as well as the lower costs for transport providers compared with home delivery. Moreover PP and APS networks make use of powerful IT tools for tracking parcels and managing returns, and international partnerships are set up for cross-border deliveries.

In spite of the major investment costs they entail, locker networks seem to be a promising solution, reducing missed deliveries and allowing for off-hour logistics operations (Augereau \& Dablanc, 2008), the main focus of this analysis is on the PP solution, due to the fact that limited number of parcels is handled by APS schemes in France.

\subsection{Main drop off networks in Europe today}

Alternative delivery networks have recently developed in all European countries, especially in northern Europe (the Swedish operator PostNord provides about 5000 distribution points to the end consumer in Sweden, Norway, Finland and Denmark), the UK, France and Germany, where e-commerce and delivery services are more mature than in the rest of Europe. The United Kingdom, Germany and France have Europe's largest online markets, which together represent 71\% of e-commerce with revenues amounting to €143.2 billion in 2011 (Kelkoo, 2012). Between 10 and $20 \%$ of shipments are delivered through a PP or locker solution. Table 1 gives a glimpse of the recent progress of selected European PP/APS networks in these three countries, with growth rates ranging from $5 \%$ to $150 \%$ since 2008 .

This trend towards an intensification of the networks has been confirmed in France, where the aggregate number of ventures serving as PP rose from 10,900 in 2008 to 18,200 in 2012, i.e. an increase of 67\%. The French system of point relais (reception points) has atypical features, such as its early development, which began 30 years ago to manage mail-order deliveries, and the large number of players, with different shareholding structures (Patier, Alligier, Bossin, \& Perdrix, 2002). As presented in the introduction, there are four competing PP network operators in France (Mondial Relay, Kiala, Relais Colis and Pickup Services), and the development of their networks is fairly similar (see below). These providers are medium-sized, whereas in most other countries, the market is dominated by one or two large operators (e.g. Hermes in Germany, which is almost the country's only PP network operator, in parallel with DHL Packstations providing APS).

\subsection{The French PP model}

The initial rise of PP operators in France derives from the development of mail-order selling during the 1980s (Augereau, Curien, \& Dablanc, 2009). Sogep - known as Relais Colis - and Mondial Relay were created by two mail-order companies, respectively La Redoute and 3Suisses, with the aim of improving the efficiency of their shipping services. These operators expanded their networks during the 1990s, driven by a sequence of postal strikes, and are now among the biggest players on the French market. The spread of e-commerce opened the way for two additional PP companies, the Belgian firm Kiala and Pickup Services, a French start-up created in 2004. The rise of these companies 
Table 1

Trends for reception point networks in Europe.

\begin{tabular}{|c|c|c|c|c|c|c|}
\hline Company & Service type ${ }^{*}$ & Country & $\begin{array}{l}\text { No. sites } \\
2008\end{array}$ & No. sites 2012 & Growth rate $08-12$ & Parcel volumes 2012 \\
\hline ByBox & APS & UK & 1000 & 1300 & $+30 \%$ & N.A. \\
\hline Collect Plus & PP & UK & Not available & 5000 & N.A. & N.A. \\
\hline PackStation & APS & Ger. & 1000 & 2500 & $+150 \%$ & N.A. \\
\hline Paketshop (Hermes) & PP & Ger. & 13,000 & 14,000 & $+7.7 \%$ & N.A. \\
\hline ByBox & APS & $\mathrm{F}$ & Not implemented & 170 & N.A. & N.A. \\
\hline Cityssimo & APS & $\mathrm{F}$ & 20 & 33 & $+55 \%$ & N.A. \\
\hline Kiala & PP & $\mathrm{F}$ & 3800 (with M.R.) & 4500 & $+18 \%$ & 15 million \\
\hline Pickup Services & PP & $\mathrm{F}$ & 3100 (à2pas) & 5200 & $+68 \%$ & 9 million \\
\hline Mondial Relay (Point Relais) & PP & $\mathrm{F}$ & 3800 (with Kiala) & 4300 & $+13 \%$ & 12 million \\
\hline $\begin{array}{c}\text { Relais Colis } \\
\text { (Sogep) }\end{array}$ & PP & $\mathrm{F}$ & 4000 & 4200 & $+5 \%$ & 23 million \\
\hline
\end{tabular}

Source: the authors with company data from various sources

$*$ APS = automated pack station; PP = pickup point

has not gone unnoticed by the major delivery and transport players, such as UPS and La Poste, which have shown particular interest in the IT system and e-logistics data networks set up by the two firms. As mentioned earlier, UPS and La Poste have bought Kiala and Pickup Services respectively.

Fig. 1 shows that the four current networks primarily rely on small independent local shops, such as florists, bars, tobacco shops and press kiosks. These networks have a quite similar spatial deployment and standard of service across France. Each of the operators provides online shoppers with between 4000 and 5500 pickup points across the country, i.e. a network which is almost a quarter the size of the network of post offices. In 2010, about 60 million parcels were delivered in France via PPs, i.e. approximately $20 \%$ of the total volume of parcels generated by distance selling.

Table 2 presents changes in the density of PPs for each network, showing the increase that took place for the whole French population between 2008 and 2012. However, due to the constant growth of e-commerce, it is important to point out that each PP site is now serving a larger number of online shoppers.

The continuing influx of newcomers to the end-delivery sector shows that the market has not reached saturation. In 2012, for example, the retailing chain Casino Group created an ad hoc reception service for CDiscount, a household appliance e-retailer. This network is hosted by the convenience stores belonging to the group and benefits from flows that are integrated into the inventory management system used by Casino outlets. Other retailers provide a PP option in their own outlets, such as Darty and most of the main retailing chains (Carrefour, Auchan, Monoprix, etc.). In particular grocery retailers, increasingly provide "Drive" services, which are in-store pickup services for online grocery shoppers.

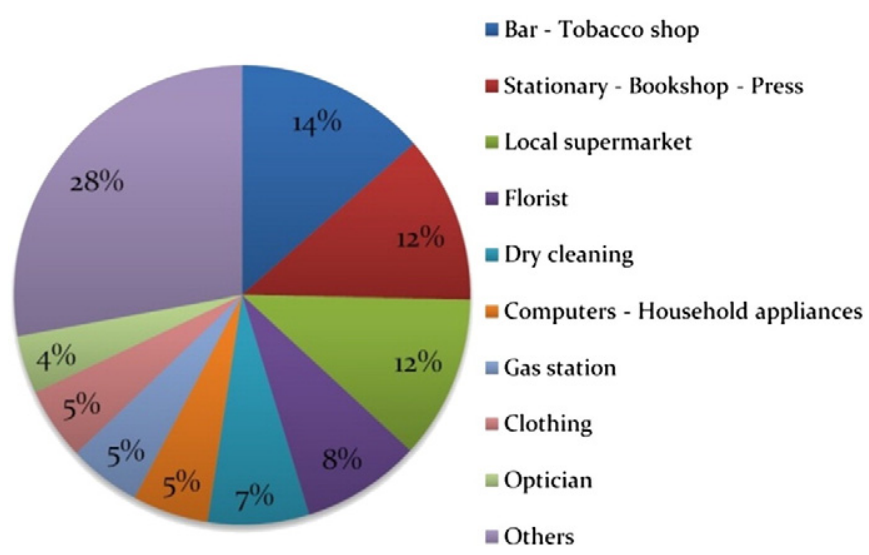

Fig. 1. Type of partner store in the pickup points network, Seine-et-Marne.

\section{Definitions and methodology}

\subsection{Defining the conceptual framework}

Our exploratory research took place in 2012-2013. We began by drafting a conceptual framework (Verschuren \& Doorewaard, 1999) to outline the main factors which guided our investigation of the features and spatial patterns of PP networks, from the operator's point of view. A graphic representation of the conceptual framework is presented in Fig. 2. The model consists of six elements. The central circle (Pickup Point Networks) represents the process of deployment led by the operator, which tends to enlarge the network by adding more sites. The main hypothesis is that PP network growth is influenced by external and internal factors such as population density, proximity to transportation nodes and socio-economic centers, and the distribution of parcel flows throughout the network. These factors, which are identified as the key elements of PP strategies, are represented by circles connected by two directional arrows due to their strong interactions. The Demographic indicators circle represents the concentration of consumers, as it is assumed that a higher population density generates greater demand for delivery services. One of the variables that represent the demographic context is thus population density. Similar variables that represent employment rate, computer ownership, Internet access and level of use are usually included in the assessment process. The Centers and nodes for city users circle represents parameters related to end-consumers' mobility and accessibility to socio-economic activities, in particular end-consumers' use of both public transport and private cars, and the density of retail outlets and commercial services, business and employment sites, cultural and leisure centers and public transportation nodes, i.e. bus stops and regional railway stations. The third circle, Parcel flow within the network, represents the volumes of parcels passing through each site and provides information on the preferences of receivers throughout the selected geographical zone. This factor is useful for evaluating the strategic value of locations and preventing saturation of the local PP network. Although it provides important insights into their performance, the data relating to this indicator is held by the PP network operators who consider it to be confidential.

The deployment of PPs is subject to two main constraints, pertaining to the retail and transport systems, represented by two semi-circles. With regard to the design of a PP network, retail activities play key logistics functions as they permit the reception, storage and delivery of parcels. The availability of retail activities and the willingness of shopowners to enter a PP network are therefore vital for successful network design. Indeed, as there is a risk of a PP becoming overloaded, in very busy areas PP operators are already competing with each other to find new shops to add to their networks. If the volume of parcels increases further, networks could reach saturation point. Additional constraints relate to the transport system, and affect the urban freight system as a whole. Roads, parking lots and public transport networks and services 
Table 2

Pick-up point density over population and e-shoppers, France 2008-2012.

\begin{tabular}{|c|c|c|c|c|}
\hline PP network & $\begin{array}{l}\text { PP per } 100,000 \\
\text { inhabitants } \\
2008\end{array}$ & $\begin{array}{l}\text { PP per } 100,000 \\
\text { inhabitants } \\
2012\end{array}$ & $\begin{array}{l}\text { PP per } 10,000 \\
\text { e-shoppers } \\
2008\end{array}$ & $\begin{array}{l}\text { PP per } 10,000 \\
\text { e-shoppers } \\
2012\end{array}$ \\
\hline Kiala & 6.1 & 7 & $1.7^{*}$ & 1.4 \\
\hline Pickup Services & 5 & 8.1 & 1.4 & 1.7 \\
\hline Point Relais (Mondial Relais) & 6.1 & 6.3 & $1.7^{*}$ & 1.3 \\
\hline Relais Colis & 6.4 & 6.6 & 1.8 & 1.4 \\
\hline Average & 5.9 & 7 & 1.6 & 1.5 \\
\hline
\end{tabular}

Source of data: interviews and FEVAD and INSEE 2013.

* Mondial Relay and Kiala shared the network until 2012.

directly influence the development and performance of delivery services that use PPs, therefore the transport system and the available infrastructure are indicated as a potential constraint that affects the strategy of network operators.

\subsection{Phases of investigation}

Our investigation combined a qualitative approach, based on a literature review and survey activities, with a spatial analysis of PP localization. These two methods provided complementary but converging results. They provided a more comprehensive picture of the variables affecting PP delivery schemes and allowed us to verify intermediate findings.

The qualitative research set out to collect data on the existing e-commerce parcel delivery system from the various stakeholders in the transport and retail systems, including web-retailers, shippers, the French public postal operator, logistics providers, PP network operators and PP partnering shop-owners. It included an analysis of official documents, academic and consulting studies, articles in the trade press and reports on postal activities and e-commerce. Data on PPs was collected from the literature and PP network operators' websites, as the official statistics are limited.

As reported in Table 3, seventeen individual face-to-face interviews were conducted by using semi-structured questions (dealing with the nature of delivery services, ICT tools and operational processes, and delivery demand/supply in urban, suburban, exurban and rural areas). The respondents were selected from among the largest transport and retail operators providing home delivery and alternative delivery services in France. The survey also involved administering questionnaires to a small sample of PP partnering shops-four for each PP network operating country-wide. The purpose of the questionnaires was to collect information on the last part of the delivery process, and to identify

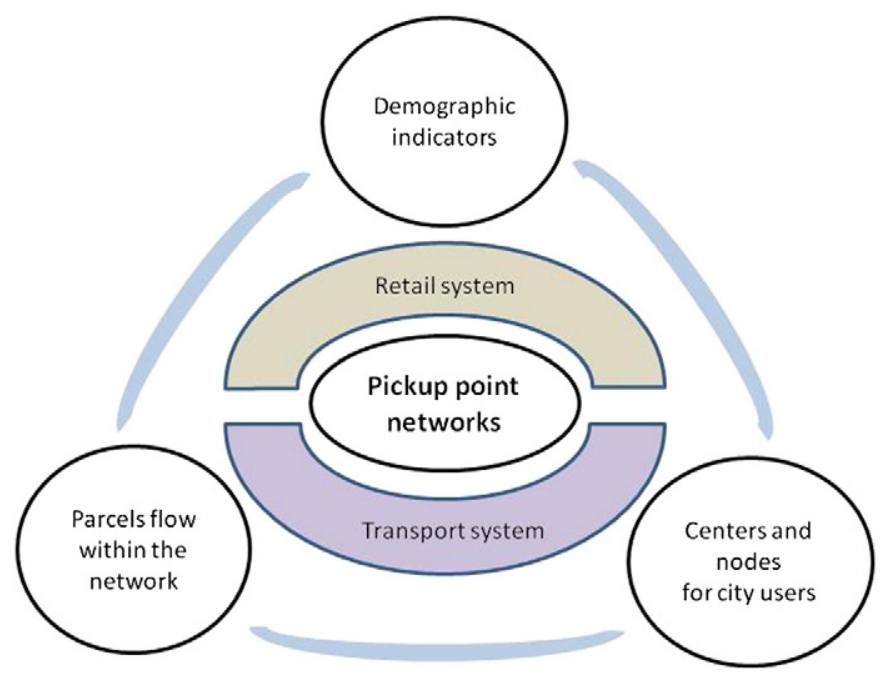

Fig. 2. The conceptual framework for a PP network, from operator's point of view. the mechanisms of last mile operations for PP services, in particular from small retailers.

The second phase of the investigation focused on a geospatial analysis of the four PP networks and an assessment of population accessibility within Seine-et-Marne, comparing urban, suburban and rural areas, using the categories defined by the French National Institute for Statistics and Economic Studies (INSEE). The selected areas were defined as follows:

- An urban area is a set of municipalities made up of an urban center with more than 10,000 jobs, where the distance between buildings is equal to or less than $200 \mathrm{~m}$.

- A suburban area is a residential area within commuting distance of an urban center and connected to it by public transportation and main roads.

- A rural area is any of the small urban units and rural municipalities outside urban and suburban areas.

The approach we adopted in order to analyze locational factors and strategies were to use spatial data and descriptive statistical variables, including nearest neighbor statistics. We used the digital spatial database for Seine-et-Marne (August 2012) provided by the Ile-de-France Institute of Planning and Urbanism (IAU). The accessibility measure took account of access distance and time for the population, where access distance was calculated by using the Euclidean distance from the centroid of each municipal zone to the nearest PP site in the four networks, and access time was calculated by using the shortest journey by car on non-congested routes from the centroid of each municipal zone to the nearest PP site in the networks. Once travel time had been computed for each relationship, we compared the access time for urban, suburban and rural municipalities, weighted by population using the data for 2009.

\section{Strategy of pickup point network operators}

\subsection{Characterization of pickup points}

According to the interviews, the main difficulty involved in running a PP service lies in the capacity to reduce delay (for many shipments, a maximum of $48 \mathrm{~h}$ from an online order to its delivery) and provide competitive prices throughout France. To meet the requirements of consumers and online retailers, PP delivery systems must guarantee coverage not only of urban areas but also less dense areas such as suburban and rural areas where delivery volumes, and therefore economic benefits, are often smaller. In addition to spatial constraints, reception points are subject to seasonal peaks of activity, for example, before Christmas and during seasonal sales.

Deciding on the location for PP sites is a two-stage process. The first is to divide the area into macro-zones on the basis of administrative criteria (post code and Department boundaries). The second is to conduct zoning on the basis of "catchment areas," in order to estimate the potential flow of parcels, on which basis, a certain number of PPs has to be integrated into the network. Surprisingly, the network operators do not specify an optimum or maximum number of parcels for a local 
Table 3

E-commerce parcel delivery system survey.

\begin{tabular}{|c|c|c|c|c|}
\hline Sector & Service & Activity & Type of survey & \# \\
\hline \multirow{2}{*}{ Transport system } & Reception points delivery services & Companies managing PP and APS networks & Interview & 4 \\
\hline & Home delivery services & Shippers, carriers, postal operator, logistics providers & Interview & 6 \\
\hline \multirow[t]{3}{*}{ Retail system } & Commercial activities & Shop-owners hosting PP & Questionnaire & 16 \\
\hline & E-commerce & Web-retailers, brick and mortar retailers, trade associations & Interview & 7 \\
\hline & & & Total & 33 \\
\hline
\end{tabular}

store to handle per day. However, the data we obtained situate the optimal flow at between 10 and 30 parcels per host outlet, even if during peak seasons this level is often exceeded. The average fee paid to participating shop-owners is $€ 0.50$ per parcel and ranges from $€ 0.15$ to 1.50 depending on the network and the type of service provided (reception, payment, returns management, recycling, etc.).

In general, parcel operators do not surcharge when delivering to remote areas, or, conversely, very central and dense areas, despite the high costs involved. According to the interviewees, standardized rates for a PP network are made possible by hidden cross-subsidies from consumers. Standard rates for domestic parcel deliveries are based on weight and size, however one of our respondents mentioned that their company is considering the possibility of also basing delivery fees on distances and deadlines.

\subsection{IT tools and operational process}

A characteristic shared by all the interviewed PP providers is the use of a technological platform designed to manage the entire distribution system. IT tools process a complex system of information flows: parcel origin and destination, transport legs, location of transshipment warehouses, location of hubs, agencies and pickup points, business opening hours and holiday times, etc. The IT platform is used to organize all this data then to apply algorithms in order to optimize flows. Data on a parcel's progress is automatically uploaded to the central system which distributes it to the different links in the chain, tracking parcels throughout the delivery process and informing supply chain operators about various matters, namely inventory management, packaging, order preparation, packing, dispatch, transport information outsourcing, consumer services and returns.

PP operators seem to be very responsive as regards adapting their network to fluctuations in parcel traffic, particularly when they detect a rising trend in the volumes to be delivered in a given area. In this situation, they attempt to recruit a new PP partner to cope with the increased demand. Network stability (maintaining a low turnover of local partner outlets) is an essential factor in order to satisfy consumer expectations.

\subsection{Network implementation criteria}

The respondents all recognized the importance of population density factors and transportation nodes, i.e. the main train and subway stations and the main road intersections. However, their site selection criteria for the four PP networks vary considerably. One PP provider said that data on internet penetration and/or household ownership of ICT equipment was taken into account when modeling the network. Another mentioned the use of trip generation models, i.e. a purchasing trip model, and also stated the importance of urban geography, housing patterns and land use classification. In some cases a distinction between areas with high rise buildings and areas with single homes is made. Delivery operations in these two types of residential areas follow different patterns, mostly because single-home areas seem to accommodate home deliveries more easily. One reason may be that a family member (such as a stay-at-home mother) may be present for more time during the day than in apartments. Another reason, mentioned several times during our interviews, is that a single home provides more potential for informal arrangements when nobody is at home (parcels can be left by the door, or hidden in the courtyard, or left at a neighbor's, etc.). Thus home delivery is preferred to use of a PP.

The respondents also underlined that once an area is covered by a certain number of points, the volume of parcels passing through each local site is closely monitored. Future development of the networks is forecast on the basis of trends in daily flows. Two respondents stressed that "response time" has to be short and that when volumes are increasing on one site, another PP has to be recruited in order to maintain a balance between all the PPs.

\subsection{Constraints on network implementation}

The respondents identified two main categories of challenges when building a PP network. The first constraint mentioned by all the respondents is the availability of a dynamic base of retail activities. Convenience stores, florists, news kiosks, etc. have become logistics players in the last mile distribution chain and play a decisive role in activating and maintaining the PP network. Shop-owners decide to provide parcel reception services both for additional revenue and in the hope of generating more in-store traffic, but the possibility of entering a network also depends on the features of their business, physical factors and site location. Some explanatory comments from PP network operators are given below.

"We cannot set up a reception point if there are no stores in the area, or if a store's manager refuses to make it a hosting site."

"In some cases, it is hard to recruit new shops. For example, in dense areas, where real estate is expensive, shop-owners are not at all interested in joining the network and sharing limited storage space."

Predictably, the interviews confirmed the high dependency of PP network design on good accessibility and the provision of good transport infrastructure, for both delivery carriers and end-consumers. Traffic congestion and mobility constraints, therefore, are among the top challenges when implementing a PP network. According to our interviews of transport operators, PP delivery operations are most efficient when they are consolidated in a medium to heavy truck able to serve 15 to 17 outlets. However in very dense areas, where only light commercial vehicles are allowed, consolidation is reduced and per parcel delivery costs increase.

\section{Identifying the spatial patterns of PP networks}

\subsection{Location as a strategic issue for efficient PP networks}

To illustrate the mechanisms that determine the location of PP networks, it is useful to identify the firms' business model. Their economic viability depends on the capacity of the network to attract and manage a sufficient volume of goods, in order to achieve economies of scale and thereby reduce the unit cost of delivering parcels and the proportion of fixed costs generated by the structure.

The increase in flows, which constitutes a primary target, must be backed up by a capillary network large enough to serve online shoppers in each area. In fact, there is a risk that distribution concentrates at certain PPs to the detriment of others that are less strategically located or less easily accessible. So while delivery consolidation helps to increase 

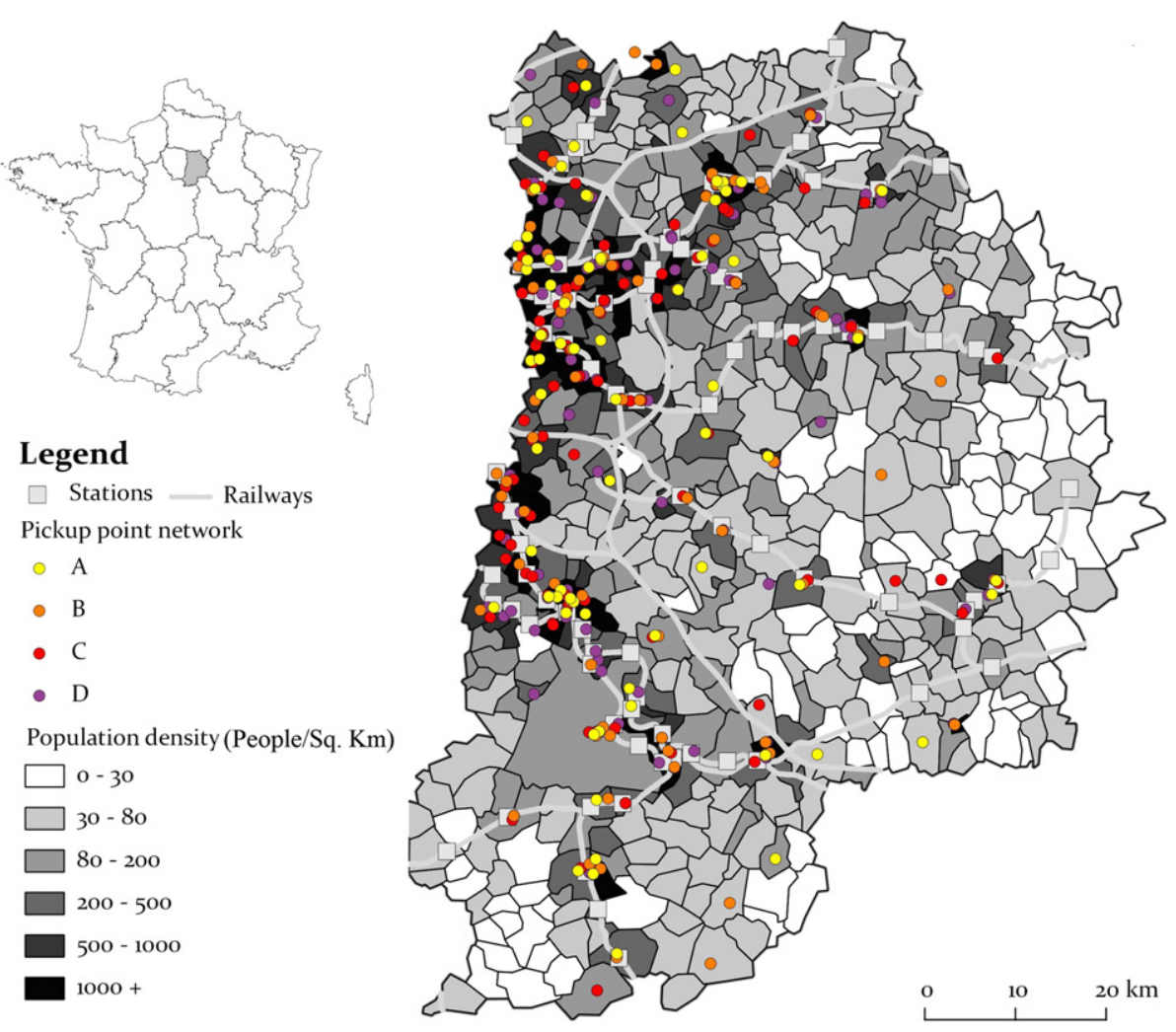

Legend

$\square$ Stations — Railways

Pickup point network

A
B
- C
D
Population density
$\square$ o- 30
$\square 30-80$
$\square 80-200$
$\square 200-500$
$\square 500-1000$
$\square 1000+$

Fig. 3. Pick-up points network in Seine-et-Marne, 2012.

the productivity of a pickup point, the flow of parcels must be appropriate to the size of the business hosting the reception point in terms of storage space and time taken up by parcel handover. Therefore the location scheme adopted by the provider must have the scope to maintain a balanced flow and achieve uniform performance in a network that must remain as stable as possible.

\subsection{PP location and distances}

In order to assess the deployment of PPs in different types of urban, suburban and rural environments in France, we took the Seine-etMarne Department as a case study. It is located in the Eastern part of the Paris region, with a population of 1.3 million and 440,000 jobs. Seine-et-Marne covers $6000 \mathrm{~km}^{2}$, of which farmland accounts for $56 \%$. The population has tripled over the past 50 years and its density across the area tends to vary substantially. Urban sprawl from Paris means the western parts of Seine-et-Marne are far more densely populated than the eastern and southern parts, where significant rural areas still remain. Densities are also higher along the three main regional railway lines.

The Paris region, which has the highest demand for parcel deliveries in the country, has high standards for delivery services ( $24 \mathrm{~h}$ and even "same day" deliveries). The demand for shipping services has generated dense PP coverage in Seine-et-Marne: the four French PP companies cover the Department with an aggregate of 391 parcel reception points. Each network offers a wide range of PPs, between 70 and 134 sites each. As shown in Fig. 3, there are a large number of PPs in the west of the Department, which is part of the Paris conurbation, where population densities exceed 1000 per square $\mathrm{km}$. More precisely, within the whole Department, PP distribution patterns show a significant positive correlation with population density, with a predictable decline in PP density in rural areas.

At the aggregate level, all the PP networks present similar locational patterns and tend to target the same areas, i.e. those with the highest population, where there is a very large number of potential partnering shops. The clustering trend is further evidenced by the dispersion index which ranges between 0.56 and 0.93 for the four PP networks. As expected, distances to the nearest PPs vary significantly: on average, the population is located $1.6 \mathrm{~km}$ from the nearest PP in urban areas, and $6 \mathrm{~km}$ in rural areas. No major differences are observed between the four networks. Discrepancies between urban and rural areas confirm the importance of car dependency issues for the rural population, while urban consumers are more likely to reside within walking distance of the nearest PP.

It is also noteworthy that a large number of PP sites are located near commuter railway stations: half the stations in Seine-et-Marne are within $300 \mathrm{~m}$ of a PP. As shown in Fig. 3, 51\% of PPs are located within $400 \mathrm{~m}$ of a station and there is a PP within $600 \mathrm{~m}$ of each regional railway station. Therefore, railway stations, which serve as functional nodes and a transit point for commuters in the Paris conurbation, are targeted as priority sites for recruiting stores to be added to the network.

\subsection{Access time}

At the aggregate level, the four networks offer widespread coverage of Seine-et-Marne, securing very short access times by car in almost the whole Department. Our calculation shown in Fig. 4 shows that PP access times in most municipalities range from 1 to $7 \mathrm{~min}$ by car and that $91 \%$ of the population is less than 10 min by car from the nearest PP. ${ }^{3}$ On average, each network provides an access time by car of between $4 \mathrm{~min}$ in urban areas and $8 \mathrm{~min}$ in exurban/rural areas.

\subsection{Location of the PP in the built-up and exurban/rural areas}

Population density patterns around PPs were examined to ascertain whether the PP densities in different zones differ, and if they do, in what way. For this purpose three zones (one urban, one suburban and one

\footnotetext{
${ }^{3}$ One drawback of this is that PPs which are located just outside the mapped area (institutional borders of Seine-et-Marne) are absent from the analysis.
} 

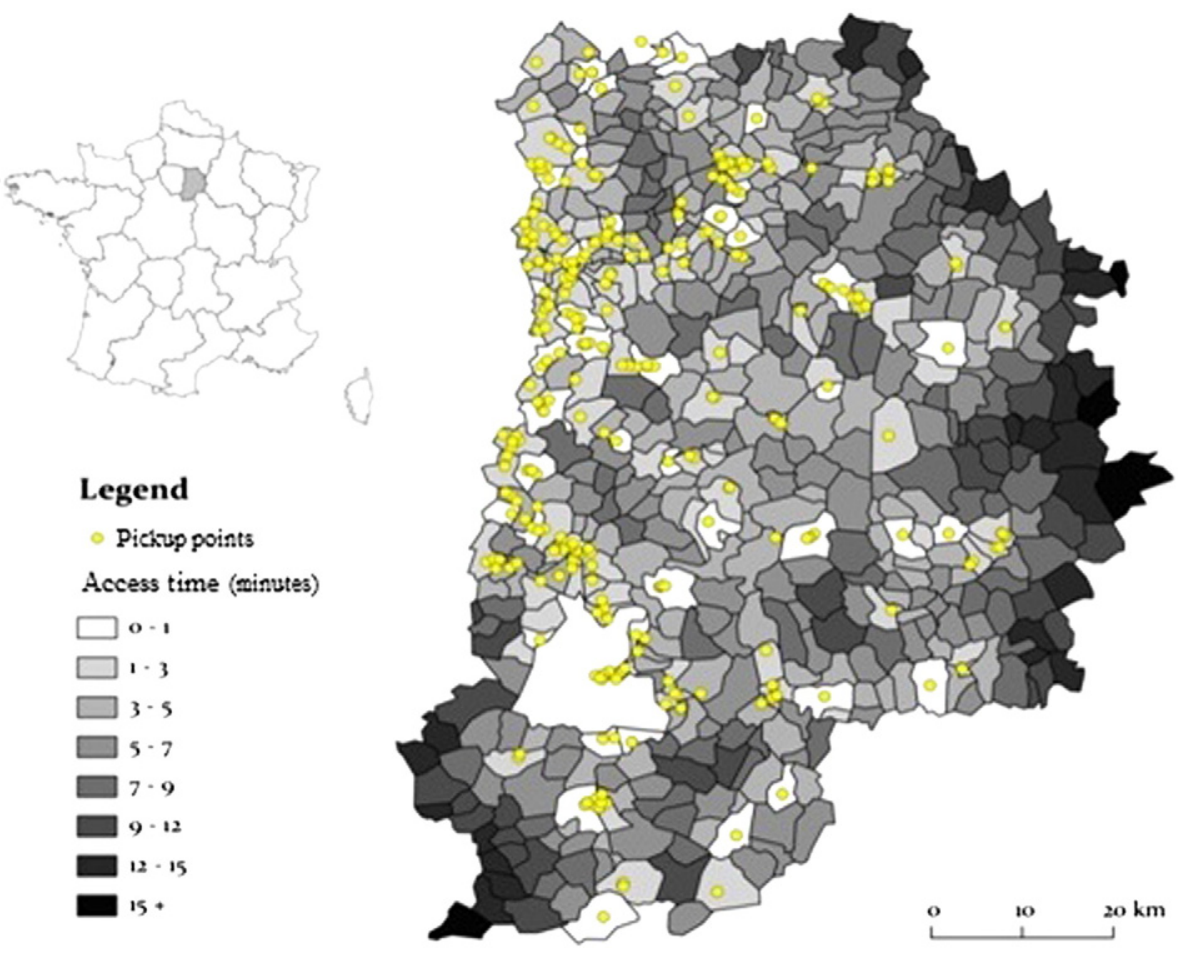

Legend

- Pickup points

Access time (ninutes)

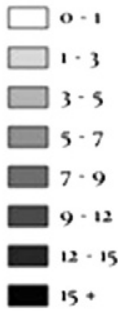

Fig. 4. Access time to PPs in Seine-et-Marne, 2012.

rural) were selected. Some interesting patterns in the distribution of PPs across different areas were noted. Fig. 5 (top) shows the inner center of Meaux, an urban area with 50,000 inhabitants and 10,000 jobs. Fig. 6 (middle) also shows PP network location for two suburban municipalities, Ozoir (population 20,000) and Gretz (population 8000) which are served by a regional railway (RER D). Fig. 7 (bottom) shows a rural area in the north of the Department, which has four small municipalities (on average 2800 inhab. each).

The first thing to emerge is that PP networks are implemented not only in cities but also in small villages of less than 3000 inhabitants. Although dense urban areas remain better served, PPs are tending to become ubiquitous, with good accessibility even in rural areas, as shown by our findings concerning PP accessibility in terms of both time and distance.

In Meaux, an urban area, we observe a concentration of PPs in the main commercial street, where there are large flows of passers-by. In suburban and rural areas, the siting of PPs reflects the structure of villages or hamlets, where amenities are usually concentrated in the "urban core". Thus it can be observed that in small settlements, PPs are more often located in the most "urban" areas than on the road intersections at the entrance of the settlements. Whenever present, regional and local train stations are the preferred targets for siting PPs.

Finally, as expected, PP density is high in the urban area and tends to be lower in low-density residential areas and rural regions, where there

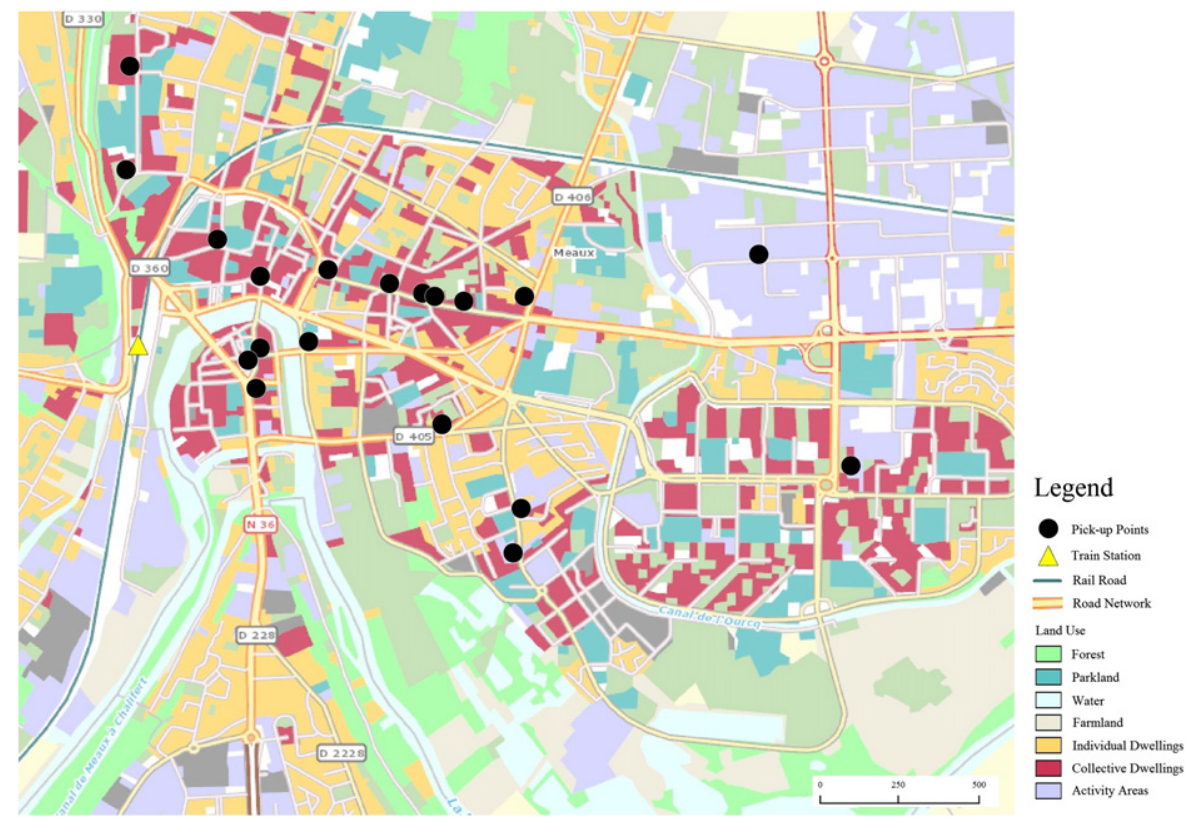

Fig. 5. Pickup point location in urban (top), suburban (middle) and rural areas (bottom). 


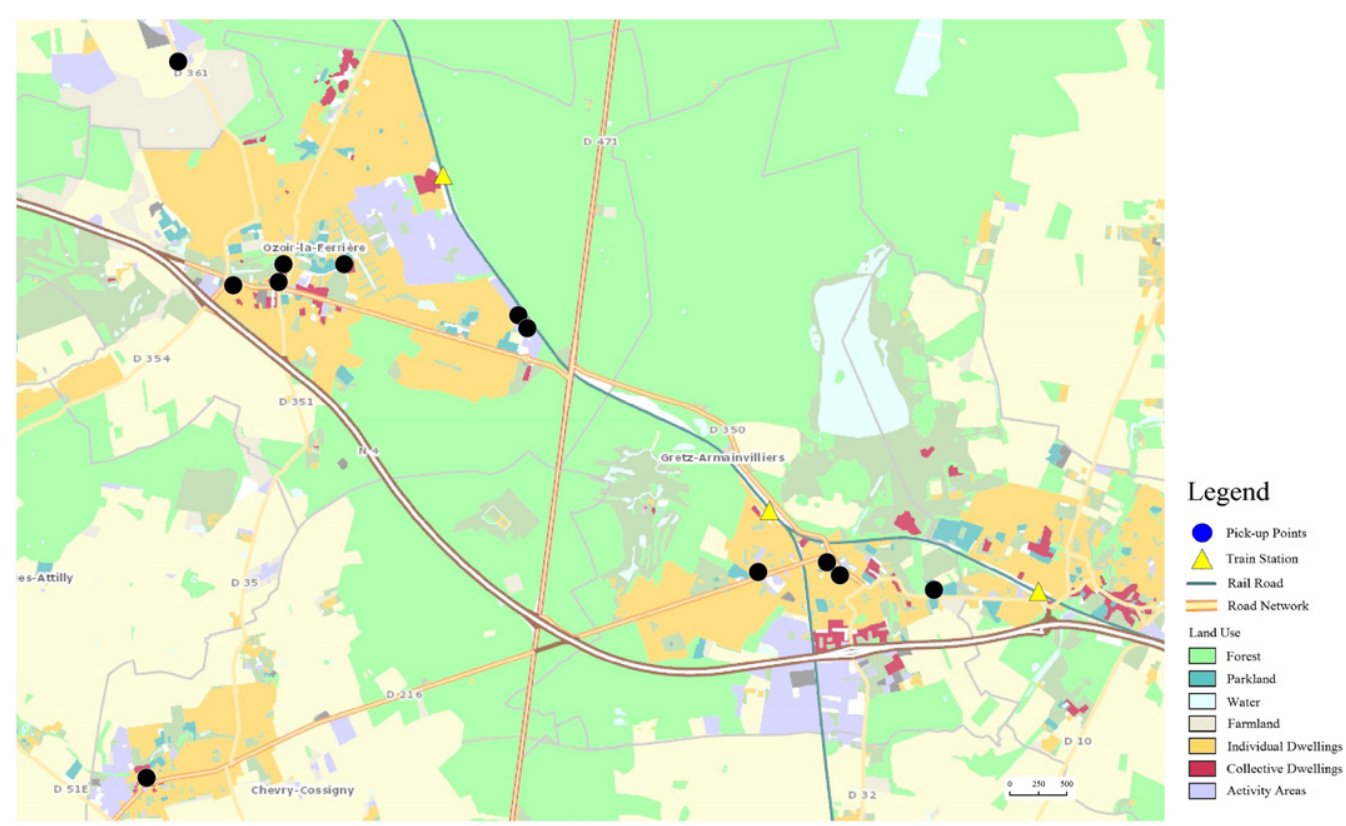

Fig. 6. Pickup point location in urban (top), suburban (middle) and rural areas (bottom).

are fewer services and amenities. However the decrease in PP coverage is more than proportional to the population decrease. As shown in Fig. 8, PPs are over-represented in urban areas (93\%) in comparison with their share of the population (83\%). This results in lower accessibility to the PP delivery option for the rural population, and may help explain the markedly higher preference for home deliveries in rural areas.

\section{Conclusion}

In this paper, by focusing on the strategy implemented by PP network operators, we have provided a description of pickup point networks and discussed the rapid growth of end-consumer deliveries in metropolitan areas and their adjacent near-rural environments. We have defined a conceptual framework that identifies the main variables and constraints that may affect the design of a PP network, and confirmed the hypotheses that underlie this framework with the results from a survey conducted among the main stakeholders (PP operators and shop-owners). The paper then presents the spatial relationships of PPs located throughout the Department of Seine-et-Marne. We have investigated the main locational patterns of PP networks, comparing urban, suburban and rural settings and examined the correlation with population density, activities and transport systems. We have measured accessibility in terms of time and distance.

Our results are threefold. First, we have documented the recent development of alternative parcel delivery services to e-shoppers in Europe, and especially in France, which has the highest rate of PP use among the main European countries. Secondly, we have described how the operators have decided to organize their PP network and assessed the relevance of population density and proximity to public transportation nodes when designing a network.

Finally, and quite importantly, our research shows that at the French national level, PPs are now a well-established alternative to

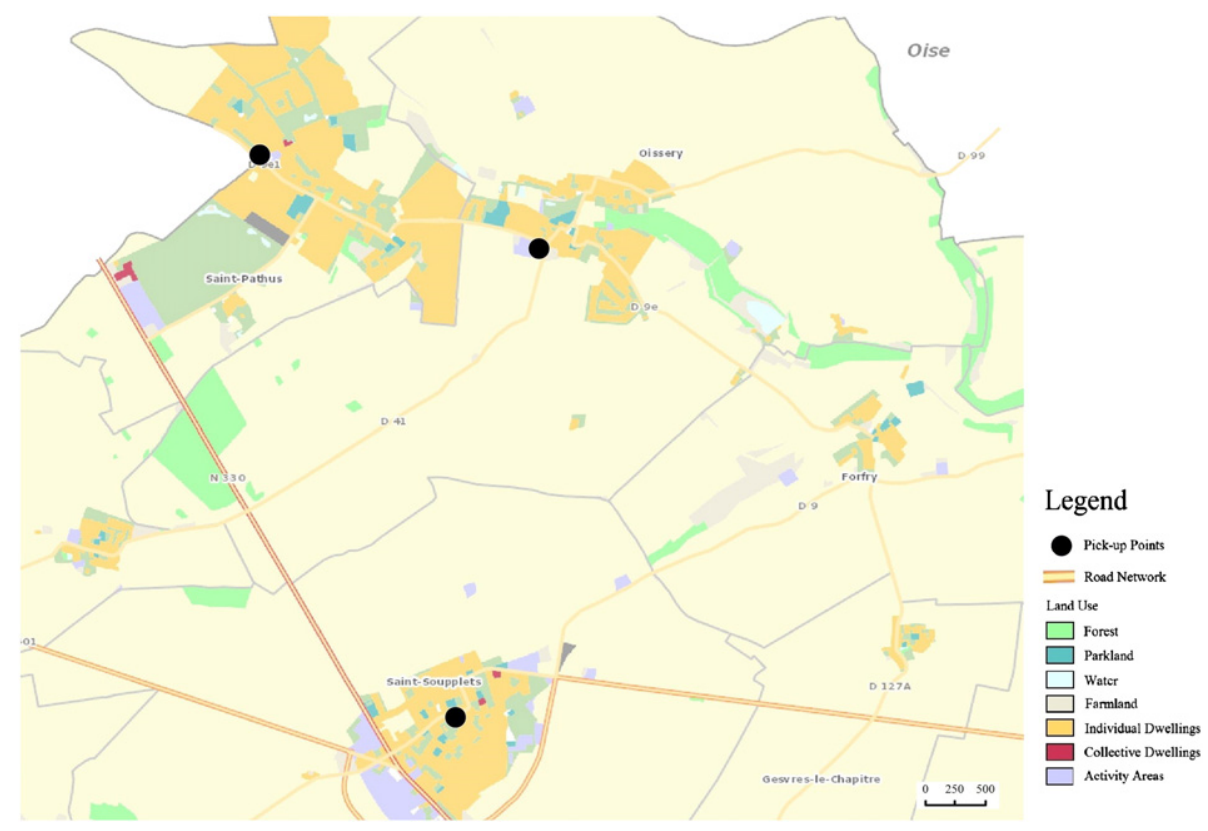

Fig. 7. Pickup point location in urban (top), suburban (middle) and rural areas (bottom). 


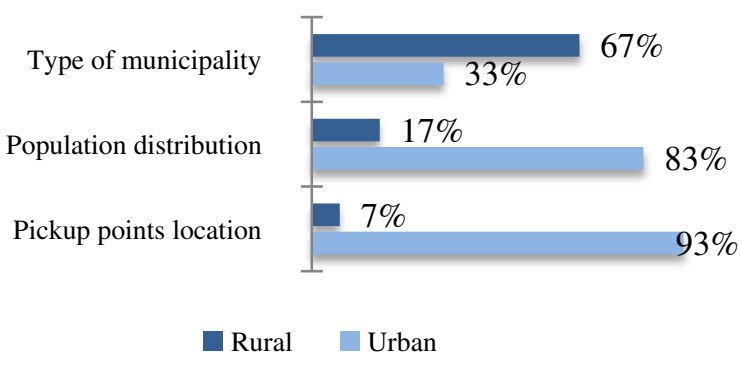

Fig. 8. Disparities between urban and rural areas.

home deliveries and their presence covers urban, suburban and rural areas. While PP density in remote areas decreases faster than population density, rural e-consumers' accessibility to PP sites has reached a viable level. This raises important questions about the overall mobility (commercial + private) related to e-commerce in urban regions.

Deliveries to end-consumers for B2C operations present many challenges, such as missed and highly fragmented deliveries. The example of France as discussed in this paper shows that PP networks make it possible to change from B2C deliveries to less costly B2B deliveries: PPs reduce the risk of missed deliveries and improve shipment consolidation. This explains their very considerable increase in France and Europe during the past 5 years. However, PP delivery services generate new types of B2B freight trips, that are not yet included in current urban freight models.

This paper lays the basis for further research focused on the identification of explanatory factors for freight and passenger trip generation in urban and metropolitan areas. It could also help those modeling city logistics traffic to better integrate the effects of e-commerce. More precisely, we suggest that PP parcel flows should be included when the next version of the urban freight FRETURB model is designed. This new version will benefit from recent quantitative survey results on urban freight patterns in the Paris region (Routhier, 2013) which do not include any specific focus on PP networks. Similarly, efforts to identify the net impacts of e-commerce deliveries on overall mobility from delivery operators' commercial trips and end-consumers' pickup trips could benefit from a detailed understanding of PP network configuration. The potential gains, in terms of reduced vehicle-kilometers, on the commercial side of truck and van movements may well be lost due to increased private car trips, especially as suburban and rural residents gain access to PP services. Finally, we consider that it would be interesting to investigate how home deliveries vary according to the type of housing. Households living in high rise buildings may have a very different pattern for home deliveries (increased use of PPs) from households in single-family homes, as some of our respondents and certain aspects of our spatial analyses have suggested. This type of research could provide interesting information for urban planners and residential developers when considering new developments by helping to quantify the demand for home delivery services that these developments may generate.

\section{Acknowledgments}

This research was carried out through a grant provided by a French national research program, PUCA (Plan Urbanisme, Construction, Architecture). It is part of a research project led by the University of Bourgogne (Motte-Baumvol \& Belton-Chevallier, 2012). We would like to thank Benjamin Motte for the geolocation data analysis and IAU (Elisabeth Gouvernal) for the digital spatial database of Seine-et-Marne.

\section{References}

ARCEP (2013). Observatoire annuel des activités postales en France, année 2011. Paris: ARCEP (36 pp.)

Augereau, V., Curien, R., \& Dablanc, L. (2009). Les relais-livraison dans la logistique du e-commerce, l'émergence de deux modèles. Cahiers Scientifiques du, Transport, 55, 63-96.

Augereau, V., \& Dablanc, L. (2008). An evaluation of recent pick-up point experiments in European cities: The rise of two competing models? In E. Taniguchi, \& R. G. Thompson (Eds.), Innovations in city logistics (pp. 303-320). New York: Nova Science Publisher Inc.

Bourdin, J. (2012). Commerce électronique. L'irresistible expansion. Paris: Le Rapports du Sénat (223 pp.)

Browne, M. (2001). E-commerce and urban transport. OECD/ECMT The impact of e-commerce on transport Proceedings. Paris: OECD/ECMT (Seminar 5-6 June).

Cairns, S. (1996). Delivering alternatives: Successes and failures of home delivery services for food shopping. Transport Policy, 3(4), 155-176.

CREDOC (2010). Le profil des acheteurs à distance et en ligne, FEVAD, La Poste, Reed CCI. (62 pp.).

Esser, K. (2006). B2C E-commerce impact on transport in urban areas. In E. Taniguchi, \& R. G. Thompson (Eds.), Recent advances in city logistics (pp. 437-448). Amsterdam: Elsevier.

European Commission COM (2012). Green Paper. An integrated parcel delivery market for the growth of e-commerce in the EU- COM 698 final. (Brussels).

FEVAD (2012). Les chiffres clés vente à distance e-commerce, Edition 2012. http://www. fevad.com/uploads/files/Etudes/chiffrescles/chiffres_cles2012.pdf (Accessed July 2013)

Gonzalez-Feliu, J., Ambrosini, C., \& Routhier, J. L. (2012). New trends on urban goods movement: Modelling and simulation of e-commerce distribution. European Transport/Transporti Europei, 50, 1-23.

Kelkoo (2012, January 26). L'e-commerce transfrontière - Conférence Acsel. Paris: L'e-commerce en Europe (http://press.kelkoo.co.uk/wpcontent/uploads/2012/01/ 25012012_Bilan-ecommerce-Acsel_-FINAL.pdf. Accessed 28 January 2013)

Moati, P. (2009). La vente à distance dans la nouvelle révolution commerciale Cahier de recherche N. 261. Paris: CREDOC, 124

Motte-Baumvol, B., \& Belton-Chevallier, L. (2012). Les effets de la vente en ligne sur les inégalites territoriales d'accès au commerce, vers un nivellement des disparités urbain-periurbain? Research description in PUCA research program Du périurbain à l'urbain. http://rp.urbanisme.equipement.gouv.fr/puca/activites/actions-periurbainurbain.htm (Accessed January 27, 2014)

Nemoto, T., Visser, J., \& Yoshimoto, R. (2001). Impacts of information and communication technology on urban logistics system. OECD/ECMT The impact of e-commerce on transport Proceedings. Paris: OECD/ECMT (Seminar 5 -6 June).

Patier, D., Alligier, L., Bossin, P., \& Perdrix, A. (2002). Les conséquences du développement de nouvelles formes de commerce sur la logistique urbaine. Paris: Ministère de l'Equipement (73 pp.).

Punakivi, M., \& Saranen, J. (2001). Identifying the success factors in e-grocery home delivery. International Journal of Retail \& Distribution Management, 29-4, 156-163.

Rallet, A., \& Perrin Boulonne, H. (2010). L'évolution du commerce à l'ère de l'économie numérique. Paris: CCIP/Prospective et Entreprise.

Routhier, J. L. (2013). French cities' urban freight surveys. City logistics research: A transatlantic perspective. Conference proceedings 50 Summary of the First EU-US Transportation Research Symposium. (pp. 9-14). Washington, DC: Transportation Research Board of the National Academies.

Schewel, L., \& Schipper, L. (2012). Shop 'till we drop: A historical and political analysis of retail goods movement in the United States. Environmental Sciences Technology, 46-18, 9813-9821.

Song, L., Cherrett, T., McLeod, F., \& Wei, G. (2009). Addressing the last mile problem. Transport impacts of collection and delivery points. Transportation Research Record: Journal of the Transportation Research Board, 2097 9-18.

Taniguchi, E., \& Kakimoto, T. (2003). Effects of e-commerce on urban distribution and the environment. Journal of Eastern Asia Society for Transportation Studies, 5, 2355-2366.

Verschuren, P., \& Doorewaard, H. (1999). Designing a research project provides methods and techniques for developing conceptually and technically sound research project. Utrecth: Lemma (215 pp.)

Visser, J., Nemoto, T., \& Browne, M. (2013). Home delivery and the Impacts on the urban freight transport: A review. Urban areas recent advances in city logistics: Proceedings of the VII international conference on city logistics, Bali, Indonesia, June 17-19 (pp. 14-31).

Wygonik, E., \& Goodchild, A. (2012). Evaluating the efficacity of shared-use vehicles for reducing greenhouse gas emissions: A U.S. case study of grocery delivery. Journal of Transportation Research Forum, 51-2, 111-126. 